\title{
Airscapes: Atmosphere as Form in Architecture/ No Molds but Modulators
}

\author{
RAFAEL BENEYTEZ-DURAN \\ Texas Tech University
}

For the past 15 years, the increased use of the terms atmosphere, atmospheric, or atmotopo attempts to capture a crucial cultural moment that weaves together different schemes of thought with myriad technologies of communication and visualization. The methods of representation are arguably more varied than ever, and with them, design methods cross all kinds of knowledge. But almost none of the elements that constitute the problem of the atmosphere are aligned under the same ideology. Therefore, addressing the atmosphere within architectural thought becomes a pressing issue today. It involves the acceptance of heterogeneities, contradictions, and antagonisms between the different ways that the term is being used. From Fumifugium: or the Inconvenience of Aer and Smoak of London Dissipated, (1661) of John Evelyn's to the implants of nature (2003) of Olafur Eliasson on weather dispositions (arrangements), nature, ecology, energy, economy, urbanism, and architecture are aligned under the context of the term "atmosphere." Embracing such differences, "Airscapes" is a collection of seven ideological schemes that frame atmosphere as form in architectural thought. "Airscapes" categorizes significant works of atmospheric activism in theory and practice through an atlas of different underlying structures of thoughts (schemes) of Western culture. "Airscapes" categorizes significant works of atmospheric activism in architecture theory and practice through an atlas of diverse underlying structures of thoughts (schemes) of Western culture. Gravity versus Atmosphere, Figure versus Ground, Island versus Clouds, Beauty versus Sublime, Quantitative versus Qualitative, Stable versus Unstable, Chronology versus Heterochrony.

\footnotetext{
AIRSCAPES

"Airscapes" could be considered as an antagonism to the term "Landscape." From a metaphorical understanding, "Airscapes" charts a projective history of disciplinary thought to explore the potentials of atmosphere as form in architecture. At the same time, the idea of opening a space of thought under the notion of an airscape leads to a debate that considers the atmosphere as a recognizable problem within the capacities of aesthetical thought: the ecumenism of all thoughts (Simondon). ${ }^{1}$ After observing that none of the past conceptions of atmosphere attract a unity of thought, this papers argues that they need to be simultaneously considered in relation to others modes of thoughts: scientific, technical, artistic, philosophical, ecological...
}

\author{
OPHELIA MANTZ \\ Texas Tech University
}

Furthermore, the use of the term "form" is not limited to the shapes and outlines of the design object that is typically conceived of by architects. The spirit of the Gestalt Theory, from many decades ago settled that the visualization of the outer, physical world depends on how we perceive and also conceive as immediate response. Nevertheless, in favor of a huge advance of the construction of our theories and practices, the robustness of the term "form" under the gaze of Gestalt Theory has reduced its significance to our capacities of visually drawing or representing objects. The use of the term "form" within this limitation becomes too weak nowadays, as it is being understood here with amplified capacities. More than related to things, "form" is related to dispositions, toggles of organization, and structures of relationships, among others. "Form" as a term has to be re-explored and re-imagined to opens its capacities to other spectrums made by non-solid objects. Form would be conceived out of the rigidity of a mold to be reconsidered as a modulator.

Atmosphere as form must be realized by this understanding of the term. "Atmosphere as form in architecture" is a statement that seeks to represent architecture out of the previous limitations of the notion of form, destabilizing stable notions that have been set on the term "form" to invite the understanding of form not as a molds but as modulator.

\section{SEVEN SCHEMES}

The term atmosphere, certainly overused, has ceased to be just a metaphor of historians. Nowadays the term implies physical, technical, and scientific realities on the one hand and on the other "an environment of aesthetic sensibility" that is presented in architecture, uniting the tangible and intangible of the physical, scientific, technical, political, and cultural world. This paper does not consider anything other than presenting the complexity of the atmosphere as a form and will resort to it through seven of the many schemes of the complex problem. The arguments presented here ruminate over the question : how do we represent something that our historical modes of thought have not yet known how to conceive? Like Lefebvre's notion of "urban," ${ }^{2}$ which is not represented by the city as physical form or the urban society, but as a complex force that acts in the interstices of both, the notion of atmosphere acts in between both the object and the subject. Due to the difficulties of focusing the question of the atmosphere between different realms of knowledge and thought, this paper works through some of the schemes that show its thematic and cultural complexity. 




Figure 1: Walking over Salt Flats, Wendover, Utah, Great Salt Lake, 2016

The seven schemes that are proposed have different degrees of complexity. Some operate underground, others on the surface. A sequence with origin in a certain triviality arises through them. Next, different planes and modes of thought will be warped to try to understand that the atmosphere as a form is not representable from only singular points of view. To think the term in just an historical way or by independent elements incapacitates its potential for theoretical discourse. The seven schemes listed as such are as follows. $1 /$ Gravity versus Atmosphere states the abuse of stability in architecture to formally counterbalance the nowadays growing atmospheric disruption within the discipline. In 2/ Figure versus Ground, the new position of the term ecology by Felix Guattari's book The Three Ecologies ${ }^{3}$ inverts the classical understanding of figure over ground to consider figure as consequence of ground. This scheme implies a reconfiguration of subjectivity and the re-imagination of the relationships between subject and medium. 3/ Island versus Clouds Departs from the theory of the atmosphere of Peter Sloterdijk ${ }^{4}$ and navigates through the phenomenologies of Maurice Merleau-Ponty ${ }^{5}$ and Edmund Husserl. ${ }^{6}$ This scheme dissolves the historical division between interior and exterior to realize medium and form under continuous fluxes. 4/ Beauty versus Sublime Follows Arthur Danto's critique on the abuse of beauty ${ }^{7}$ and how the sublime dominates the aesthetical problem of atmosphere. Atmosphere is presented in this scheme as a field of aesthetic sensibilities. In 5/ Quantitative/ Qualitative is presented how the conceptions of energy of Yves Klein and Gregory Kepes displaced the boundaries from one to another mode of thought. Certain forms of positive knowledge requires irrationalities to makes systems work. As consequence in this scheme, energy is rendered through the term atmosphere to approach both at once from an aesthetical discourse. 6/ Stable versus Unstable, between these two states exist a wide spectrum of points of equilibrium called metastable. Based on Gilbert Simondon's theory on the "Individuation," ${ }^{8}$ this scheme presents new understandings of form evolution. Finally, in 7/ Chronology versus Heterochrony anchored on George Kubler theory of time in art history periodization, ${ }^{9}$ the search of the profoundness of atmospheric history claims to rebuild the project of architecture history. From the present to the past this scheme seeks to devise strategies to frame a history of atmospheric forms by following heterochronic patterns.

\section{CHRONOLOGY VERSUS HETEROCHRONY}

Within the scope of this conference, based on the idea of "New Instrumentalities," this paper focuses on the last scheme mentioned: Chronology vs Heterochrony. The intention is : A/ To transmit the understanding that the historical profoundness of the atmosphere as form in architecture, it must challenged the systems of organizations of the project of history. (A history project based on the use of a very limited understanding of the term form as was presented in the beginning of this writing). The intention of this writing is not to face how to start this monumental work, but to reflect on it. B/ To reveal that the currency of atmosphere as form can call the past to be understood in the present by projecting the present towards the past. C/ To see the possibilities that this projection has to liberate the practice of the heaviness of the written history to invite other solutions and "dispositions." This projection, based in George Kubler proposal, is itself the consideration that the project of history is not chronological. The objects, matter Kubler's observation, are not a result of technical and aesthetical refinement of process, are not only evolutions in one only direction of time. Forms are open and inclusive with other forms and systems that have appeared either now or before, before and now. To show the imperative mode of thought of written history and its results a first paragraph will show a chronological current of time. A second paragraph will present an heterochronical pattern to explore the possibility of the retroactive projection.

\section{CHRONOLOGY}

Since when has the term atmosphere been in architecture? Prior to the plenitude of the Modern Movement, an interest in the atmosphere remained relatively low among historians of art and architecture. Some of them, such as Theodor Lipps ${ }^{10}$ August Schmarsow, ${ }^{11}$ Aloïs Riegl, ${ }^{12}$ Heinrich Wölfflin, ${ }^{13}$ and Wilhelm Worringer, ${ }^{14}$ who were followers of the German 


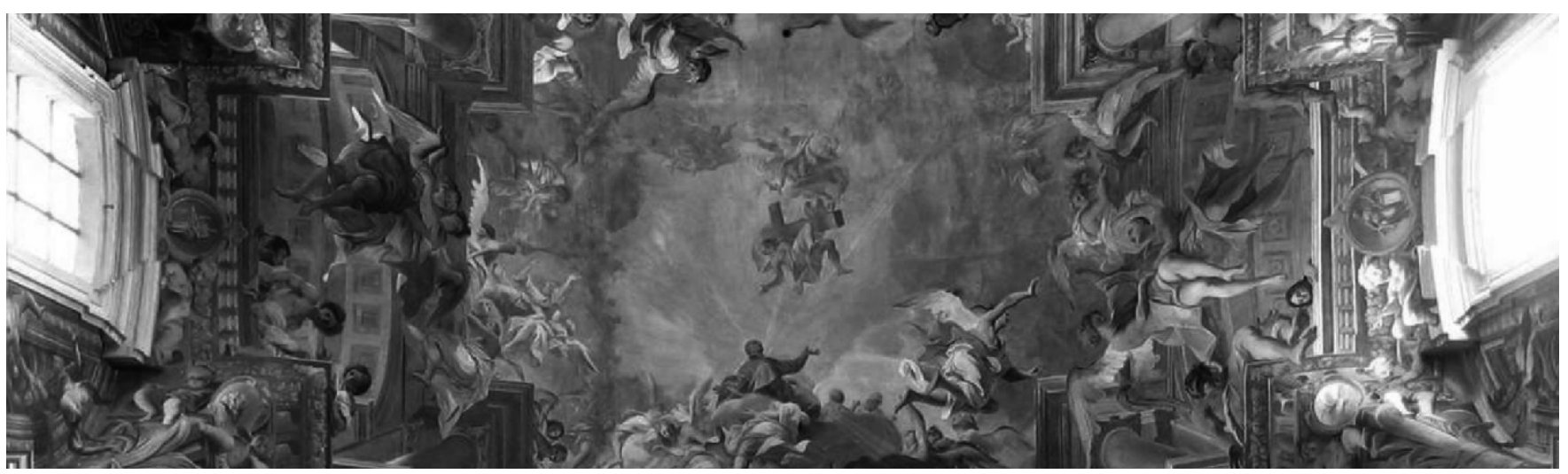

Figure 2: Allegory of the jesuits missionary work, detail, Andrea Pozzo, 1650, Sant'Ignazio , Rome, Italy

environmental school ${ }^{15}$ and were perhaps still moved by the still-relevant aesthetic environments of Impressionism and Expressionism, approached the subject in several ways without being able to confine it into a stable body for theory. The irruption of rational positivism in architecture, ${ }^{16}$ which would underpin the "modern project," frustrated the opportunity of expressionism represented in the works of Bruno Taut and Paul Scheerbart - an unexplored reef to which Iñaki Ábalos has called the "repressed image" ${ }^{17}$ of the modern project.

In his exploration of the space of the Gothic cathedral, Worringer tries to express "what the stones emanate" to stage the feeling of the Gothic man in his architecture. A feeling that led to restlessness and anguish in front of the spirit of the times, stirred by the "cosmic terror." Thus the Gothic cathedral is presented to reach the only thing that could then be represented, the sublimity of its restlessness and its darkness "to feel caught in an intoxication for his savior." ${ }^{18}$ For Worringer abstract space has no life, while the atmospheric "has an inner life that immediately acts on our senses." ${ }^{19}$ The atmosphere in architecture was represented then between attributes and nouns of "the atmospheric." Among them, "the indeterminate" and "the infinite" are the common characteristics of both the Gothic and the Baroque, which would distance them from the Renaissance's object of representation. Thus Wolfflin will unite both in a common sense of the "feeling of infinite space." ${ }^{20}$ In his observations on Baroque architecture, Wölfflin made use of the term "atmosphere" repeatedly to show the blurry and confusing, summed up in his own words: "On less perception, more atmosphere." ${ }^{21}$ In the term atmosphere Wölfflin found a way to narrate the sublimity of this space. A space characterized by spatial blur and the blurring of frames, where light, different from the Renaissance, was used to promote the dissolution of boundaries and planes. If the term atmosphere helped Wölffin to focus his attention and analysis on the Baroque space, then it is also good to note that he did it in a metaphorical way that above all emphasized the luminous characteristics of the space. The matter in question was the treatment of light and its effects, be it on space itself on in paintings. ${ }^{22}$ The term atmosphere was used to praise an untraceable and immense reality beyond space and represented in the baroque extasis - the lived emotion in front of that reality.

Through light, the atmosphere also reachedthe Enlightenment. Between the romanticism and the Enlightenment would be found the watercolors of Joshep Gandy. Those represented the spaces of the architect Sir John Soane through an emphasis on the tracing of light. Its object was to transmit, with all possible intensity, the expressive plastic values of the stone forms, which submerged in a dense and deep environment, reinforced the inert value of atavistic time. For Soane, light was the true architectural issue. To represent light was at the same time to represent architecture.'

On the other hand, making use of the "lumiére mysterieuse,"23 Etienne Boullée radicalizes in an exemplary way the use of light, which is considered here as a "construction material." Everything that happens in Newton's Cenotaph is subject to a luminous situation. The sum of the spherical surface plus the light is able to represent the celestial dome in the day and in the night. Boullée removes the interior of the architectural space to represent the interior of the cosmic space.

\section{HETEROCHRONY}

Is this not a way of doing that Boullée Cenotaph would have an echo in the work "The Weather Project" $(2003)^{24}$ by Olafur Eliasson, where he introduces into the interior space of the Tate Modern nothing other than the sun? To think of Newton's Cenotaph from "The Weather Project" is like thinking of Michelangelo's "Moses" from Rodin's "Thinker." As a stark difference between then and now, beyond light, there would be a contemporary consideration, much more complex and varied in which so many disciplines may consider Nature itself as "Construction Material." With the enunciation of the heterochronic, jumps in the history of art and architecture, understood as a system, lead us to a greater contingency and potentiality to think about our time. As a first example, the representation of nature in the Baroque and Jean Nouvel's project for the Cartier Foundation acquires special value 




Figure 3: Cenotaph for Newton, 1784, Etienne Louis Boullee.

in this sense. In both cases there is a strategic blurring that implies a relationship of infinity. The Cartier Foundation uses the contemporary resource of the reflection and transparency of glass in the contemporary metropolis to evoke a picturesque world that arises inside a plot whose garden is the real object of work. As if they were large fragments of the curtain wall industry, an organization of parallel glass planes dissolve the body of the building almost completely. As if the whole building were just a deep facade, or a screen that reflects the world that surrounds it, Nouvel's project, above all, builds the illusion of a garden lost among the images of the city. Included so many times among examples of atmospheric architecture, the Cartier Foundation exemplifies something more than a dissolution of objectuality in architecture, architecture as surface or the infinity of atmospheric space, it also implies a link to the contemporary of the image summarized in the flat and polished in which our contemporaneity looks. It is a prefigured space of what little later floods our daily reality: the screen in which the world is presented to us. It shows the complex aesthetic framework in which the condition of the contemporary manifests itself between the effects and modes, in a condition of environment or the atmosphere as a form. Where has the historical material opacity of architecture remained in this formal simplicity and tremendous conceptual complexity?

\section{CONCLUSION}

To dismiss the notion of forms, already considered in the written history of architecture, in favor to embrace the notion of atmosphere that is presented in this essay, implies that the project of architecture history should be re-written. This text has the suspicion that it is not possible to think the atmosphere as form in architecture if the historical used of the term is not challenged or augmented outside of the notion of form that comes to us basically from the Gestalt Theory. As consequence all theoretical explorations made by following the current written history of architecture are not representing the problem of atmosphere with all its complexity. That history does not consider the term form in the mode that can capture the problem. As instrumentality this scheme present how much our mental habits can blind the spots where things happen, or how much we can't find the result of our searches just because we do not use the instrumentalities that permit us to capture them. Other 6 schemes navigate within these habits to reveal where things are hiding spots or erasing regions of reality. 


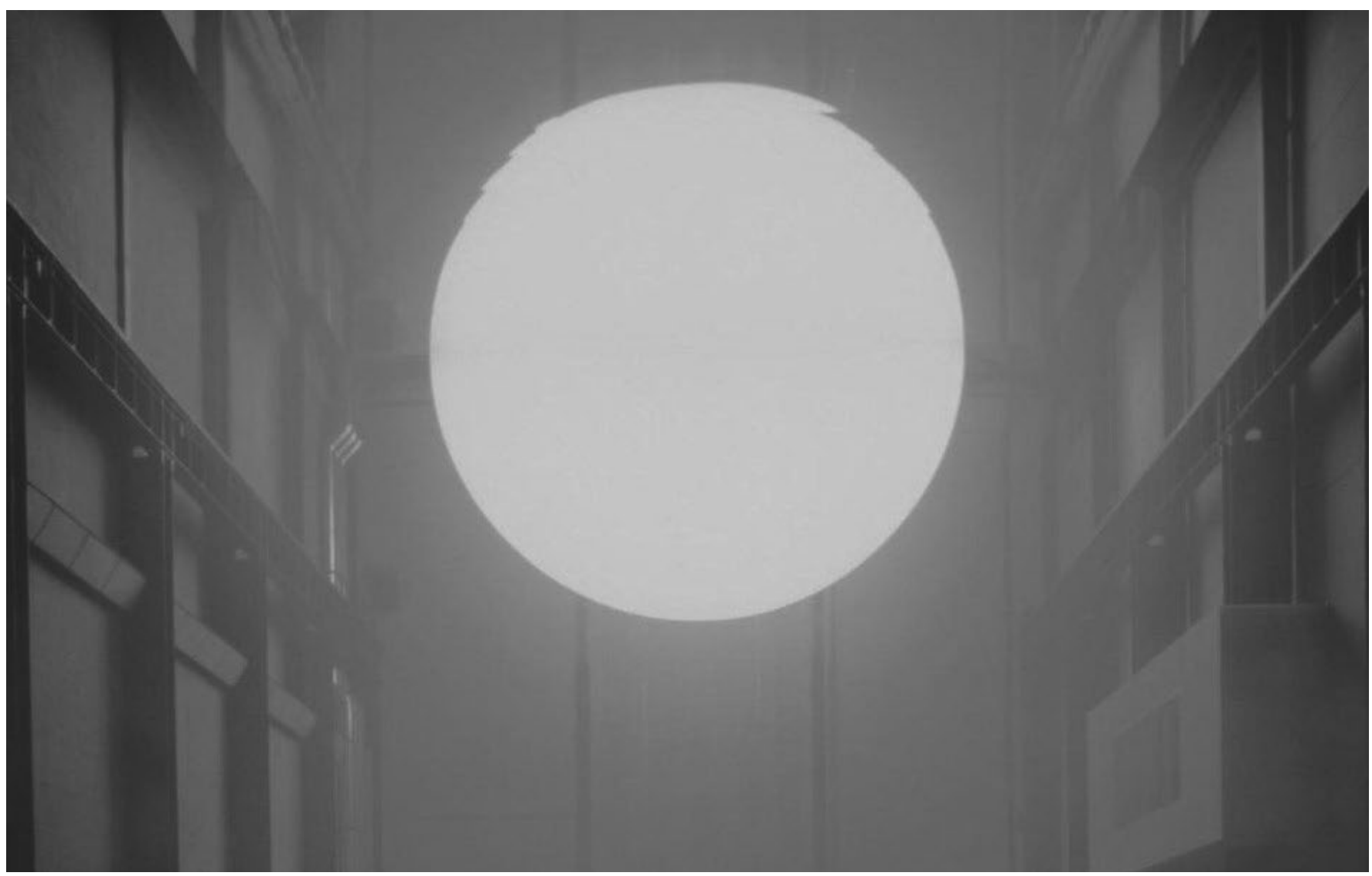

Figure 4: Weather Project,2003, Olaffur Eliasson. Tate Modern, London.

\section{ENDNOTES}

1. Simondon, Gilbert, "El modo de existencia de los objetos tecnicos" / "On the Mode of Existance of the Technical Objets" Prometeo libros, 2007, pg 178. The term "ecumenism" is used by Simondon out of the religious connotations.

2. The term "urban" as Henr'i Lefebvre use it, see "El derecho a la ciudad" (The right to the city) - (Le droit a la ville) 1968 Editor: Capitan Swing, 2014. pg 88.

3. Guattari, Felix, Deleuze, Gilles, Las Tres Ecologias (The Three Ecologies) Editor Pretextos 2007.

4. Sloterdijk, Peter, Spheres III: Foams (Esferas III: Espumas) Editor: Siruela, 2004.

5. Merleau-Ponty, Maurice, Phenomenology of Perception, Editor: Routledge, London, 2012.

6. Husserl, Edmund, Problemas Fundamentales de la Fenomenologia, Editor: Alianza, Madrid 1994

7. Danto, Arthur, The Abuse of Beauty, Aesthetics and the concept of Art, Editor: MIT Press Jstor, Cambridge, 2002.

8. Simondon, Gilbert, La individuacion a la luz de las nociones de forma e informacion, Editor: Cactus Cebra, Buenos Aires, 2009.pg 178.

9. Kubler, George, The Shape of Time, Editor: Yale University Press, Yale 1962.

10. Lipps, Theodor, Los fundamentos de la estética (The aesthetical fundamentals) Editor: Daniel Jorro, Madrid 1924. With interest in the concept of Einfühlung.

11. Schmarsow, August, Das Wesen der architektonischen Schöpfung, Karl W. Hiersmann, Leipzig, 1894

12. Riegl, Alöis, Die spätrömische Kunstindustrie nach den Funden in Österreich (The late-roman indiustrial art), Editor: Visor, Madrid 1995.

13. Wölfflin, Heinich, Renaissance y Baroque, Editor: Paidós, Barcelona, 1991.

14. Worringer, Wilhelm, The essence of gothic's style, Editor: Nueva Vision, Buenos Aires, 1957.

15. Prieto, Eduardo, Maquinas o Atmósferas, Tesis Doctoral, Madrid ETSAM, 2014, pg 405.
16. Abalos, Iñaki, Bruno Taut, Escritos, 1910-1920, Editor: El Croquis, Madrid, 1997 pg 8.

17. Ibidem 7

18. See Prieto, Eduardo, Maquinas o Atmósferas, Tesis Doctoral, Madrid ETSAM, 2014, pg 406.

19. Author translation from Ibidem $\mathrm{p} 406$.

20. Citated by Prieto, Eduardo, Op. Cit p 409.

21. Ibidem pg 410 Ibidem 11.

22. See Art works in Saint ignacio Church of Rome, 1650

23. "lumiére mysterieuse" Used term by Etienne Boullée writtings.

24. Eliasson, Olafur, "The Weather Project," Tate Modern, 2003. 